TAMADDUN : Jurnal Pendidikan dan Pemikiran Keagamaan

P-ISSN : 1693-3941; E-ISSN : 2722-2632

Vol. 22 No.1 Bulan Januari Tahun 2021

\title{
ANALISIS PERNYATAAN VISI \\ SEBAGAI RENCANA STRATEGIS PERGURUAN TINGGI MUHAMMADIYAH
}

\author{
Abdul Kholid Achmad ${ }^{1}$, Sutiah, ${ }^{2}$ Mohammad Ahyan Yusuf Sya'bani ${ }^{3}$ \\ ${ }^{1}$ Universitas Muhammadiyah Gresik \\ Email : abdkholidachmad@umg.ac.id \\ ${ }^{2}$ Universitas Maulana Malik Ibrahim Malang \\ Email :sutiah@pai.uin-malang.ac.id \\ ${ }^{3}$ Universitas Muhammadiyah Gresik \\ Email : ahyanyusuf@umg.ac.id
}

\begin{abstract}
Abstrak: Bagai nakhoda kapal, pemimpin universitas memiliki pantai tujuan sebagai ilustrasi yang dituangkan dalam visi dan misi universitas sebagai gambaran konseptual tentang arah tujuan yang diinginkan atau dicita-citakan di masa depan. Melalui pernyataan visi, perguruan tinggi dapat memberikan gambaran arah rencana strategis organisasi kepada seluruh stakeholders untuk memenangkan persaingan dan mencapai tujuan. Penelitian ini menggunakan Analisis Konten (Content Analisis) dengan jenis Analisis Penunjukan (Designation Analysis) atau juga disebut dengan (Subject Mater Content Analysis). Temuan penelitian ini menunjukkan bahwa dari 57 Universitas Muhammadiyah sebagai lokus penelitian, terdapat 7 kecenderungan konsep tertinggi sebagaimana teranalisis dari pernyataan visi yang digunakan sebagai berikut: (1) konsep pengembangan catur darma terdapat 43 pernyataan (75\%), (2) konsep keunggulan terdapat 40 pernyataan (70\%), (3) konsep pengembangan IPTEK terdapat 28 pernyataan (28\%), (4) konsep pengembangan karakter terdapat 9 pernyataan $(15,7 \%)$, (5) konsep penelitian terdapat 3 pernyataan $(5,2 \%)$, (6) konsep pengabdian masyarakat terdapat 2 pernyataan $(3,5 \%)$, dan (7) konsep tata kelola terdapat 1 pernyataan $(1,7 \%)$. Diperlukan optimalisasi visi sebagai rencana strategis oleh Universitas Muhammadiyah khususnya pada konsep penelitian, pengabdian masyarakat dan tata kelola untuk tercapainya visi Persyarikatan Muhammadiyah dan tujuan serta fungsi pendirian perguruan tinggi sebagaimana Undang-undang Nomor 12 Tahun 2012.
\end{abstract}

Kata Kunci : Visi; Rencana Strategis; Analisis Konten; Perguruan Tinggi; Muhammadiyah

\section{PENDAHULUAN}

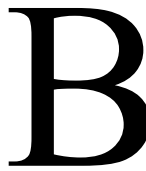
erdasarkan tujuan berdirinya perguruan tinggi yang tertuang dalam Undang-undang Nomor 12 Tahun 2012 tentang Pendidikan Tinggi adalah: (a) berkembangnya potensi mahasiswa agar menjadi manusia yang beriman dan bertakwa kepada Tuhan Yang

TAMADDUN Homepage : http://journal.umg.ac.id/index.php/tamaddun 
TAMADDUN : Jurnal Pendidikan dan Pemikiran Keagamaan

P-ISSN : 1693-3941; E-ISSN : 2722-2632

Vol. 22 No.1 Bulan Januari Tahun 2021

Maha Esa dan berakhlak mulia, sehat, berilmu, cakap, kreatif, mandiri, terampil, kompeten, dan berbudaya untuk kepentingan bangsa; (b) menghasilkan lulusan yang menguasai cabang Ilmu 
TAMADDUN : Jurnal Pendidikan dan Pemikiran Keagamaan

P-ISSN : 1693-3941; E-ISSN : 2722-2632

Vol. 22 No.1 Bulan Januari Tahun 2021

Pengetahuan dan atau Teknologi untuk memenuhi kepentingan nasional dan peningkatan daya saing bangsa; (c) menghasilkan Ilmu Pengetahuan dan Teknologi melalui penelitian yang memperhatikan dan menerapkan nilai Humaniora agar bermanfaat bagi kemajuan bangsa, serta kemajuan peradaban dan kesejahteraan umat manusia; dan (d) terwujudnya pengabdian kepada masyarakat berbasis penalaran dan karya penelitian yang bermanfaat dalam memajukan kesejahteraan umum dan mencerdaskan kehidupan bangsa.

Secara kuantitas perkembangan dunia pendidikan di Indonesia khususnya perguruan tinggi menunjukkan laju yang menggembirakan. Menurut data Statistik Perguruan Tinggi tahun 2019 sebaran perguruan tinggi sebanyak 4.621 yang terdiri dari Universitas; 633, Institut; 238, Sekolah Tinggi; 2.501, Akademi; 909, Akademi Komunitas; 36, Politeknik; 304. Dengan jumlah perguruan tinggi negeri maupun swasta sebagaimana data tersebut, dipastikan persaingan antara universitas semakin menantang untuk memberikan pelayanan yang terbaik kepada masyarakat dalam rangka membuktikan sebagai universitas terbaik.

Sebagaimana laporan webometric yang dirilis pada bulan tahun 2020 melalui website resminya, 10 besar perguruan tinggi Indonesia masih menempati urutan yang masih jauh dari negara lain. Di Asia Universitas Indonesia menempati rangking ke 694, Institut Teknologi Bandung rangking ke 896, Universitas Brawijaya rangking ke 1178, Universitas Teknologi Sepuluh Nopember rangking ke 1220, Telkom University rangking ke 1447, Universitas Gadjah Mada rangking ke 1496, Universitas Airlangga rangking ke 1551, Universitas Sumatra Utara rangking ke 1575, Universitas Diponegoro rangking ke 1753, Universitas Sebelas Maret UNS Surakarta rangking ke 1913. Sedangkan menurut QS World University secara peringkat sebagaimana hasil survei yang dilakukan oleh lembaga Quacquarell Symonds (QS) 10 besar terbaik di Indonesia adalah; Universitas Gadjah Mada (peringkat 254 dunia), Universitas Indonesia (peringkat 305 dunia), Institut Teknologi Bandung (Peringkat 331 dunia), Universitas Airlangga (peringkat 512-530 dunia), Institut Pertanian Bogor (peringkat 513-540 dunia), Institut Teknologi Sepuluh Nopember Surabaya (peringkat 751-800 dunia), Universitas Bina Nusantara (peringkat 801-1000 dunia), Universitas Padjajaran (peringkat 801-1000 dunia).

Dalam persaingan yang sedemikian ketat secara nasional maupun internasional dibutuhkan kerja keras yang melibatkan seluruh komponen perguruan tinggi. Pelibatan komponenkomponen civitas akademika dibutuhkan kemampuan pimpinan untuk merencanakan, mengorganisasikan, mengarahkan, dan mengkomunikasikan seluruh komponen dalam perguruan tinggi agar dapat memenangkan persaingan. Untuk dapat melakukan semuanya diperlukan visi organisasi sebagai rencana strategis yang dipedomani oleh seluruh civitas akademik.

Setiap organisasi terbuka maupun tertutup sebagaimana halnya perguruan tinggi memiliki mimpi yang akan dicapai dalam kurun waktu jangka dekat maupun jangka panjang. Mimpimimpi tersebut kemudian digambarkan dalam sebuah rencana strategis untuk dapat 
dikomunikasikan melalui media teks, visual maupun verbal kepada seluruh anggota organisasi agar memberikan pemahaman dalam pencapaiannya.

Bagai nakhoda kapal, pemimpin universitas memiliki pantai tujuan sebagai ilustrasi yang dituangkan dalam visi dan misi universitas sebagai gambaran konseptual tentang arah tujuan yang diinginkan atau dicita-citakan dimasa depan (Gazpers, 2004); (Haim 2005); (Pitts \& Lei 2006); (David 2009); (Porth 2003). Dengan visi organisasi pemimpin dapat mengarahkan, memotivasi, menggerakkan, mempersatukan dan merangsang pencapaian kinerja organisasi untuk mencapai tujuannya. Berbagai macam pernyataan visi organisasi memberikan gambaran arah rencana strategis organisasi. Melalui penjabaran visi, misi dan tujuan, program dan kegiatan, pemimpin organisasi dapat memberikan pemahaman yang selanjutnya dapat menggerakkan anggota organisasinya dengan gaya kepemimpinan dan kompetensinya sebagai bagian dari pengejewantahan visi dan misi agar dapat dioperasionalkan.

Definisi visi telah banyak dikemukakan para ahli di antaranya Wibisono yang menyatakan bahwa visi adalah serangkaian kalimat yang memberikan pernyataan cita-cita atau impian organisasi yang ingin dicapai dalam periode tertentu (want to be) (Wibowo.2014). Sedangkan Kotler menyatakan bahwa visi adalah ekspresi tujuan organisasi dalam produk dan layanan yang ditawarkan pada kelompok masyarakat yang dilayani terhadap nilai-nilai yang diperoleh serta aspirasi dan cita-cita masa depan (Nawawi.2000).

Visi bukan hanya slogan namun sebagai guideline mencapai tujuan organisasi yang dipikirkan dengan sungguh-sungguh untuk membantu pencapaian, pemenuhan apa yang ingin dicapai (Hamdan.2001). Visi yang terumuskan sebagai gambaran masa depan juga menjadi landasan pengembangan yang sistematis oleh pimpinan universitas (Suyanti. 2011). Sebagaimana Aktan, bahwa perencanaan strategis memerlukan empat komponen yakni visi, misi, strategi dan pelaksanaan (Aktan, 2003)

Visi sebagai realitas mimpi yang tertulis memiliki banyak standar sebagai ukurannya. Pada aspek pribadi pimpinan organisasi, visi dapat menggambarkan kepimpinan seseorang, visi juga dapat menggambarkan rencana strategis pencapaian standar yang sudah digariskan atau ditentukan oleh lembaga atau organisasi tertentu. Beberapa standar yang dapat dijadikan acuan pembuatan visi adalah Undang-undang Nomor 12 Tahun 2012 tentang perguruan tinggi dengan rumusan pengajaran, penelitian dan pengabdian, Webometrik dengan indikator dengan indicator Presence, Visibility, Openness dan Excellence (Rahardja.2017), Word Class University (WCU) dengan indicator Academic reputation, employer reputation, faculty/student ratio, citation per faculty, international student ration, dan international staff ratio, ISO 9001 dengan indicator Customer Focus, Leadership, Involvement of people, Process approach, system approach to management, continual improvement, factual approach to decision making, dan mutually beneficial supplier relationship (Mulyono.2006), dan Times Higher Education. 
TAMADDUN : Jurnal Pendidikan dan Pemikiran Keagamaan

P-ISSN : 1693-3941; E-ISSN : 2722-2632

Vol. 22 No.1 Bulan Januari Tahun 2021

Untuk itu penelitian ini bertujuan untuk mengidentifikasi kecenderungan visi Perguruan tinggi khususnya Universitas Muhammadiyah sebagai rencana strategis perguruan tinggi sebagai gambaran pencapaian tujuannya. Dengan diketahuinya kecenderungan tersebut diharapkan dapat memberikan arah dan peta kebijakan Majelis Dikti Pimpinan Pusat Muhammadiyah dalam pembinaan, evaluasi dan pengembangan.

\section{Visi Perguruan Tinggi Muhammadiyah}

Muhammadiyah sebagai organisasi yang memiliki konsentrasi terhadap bidang pendidikan sejak didirikan oleh K.H. Achmad Dahlan 18 November 1912 tidak diragukan lagi kiprahnya dalam pengelolaan lembaga yang dinaunginya (Nuryana. 2017). Dalam pandangan Muhammadiyah bahwa kunci kemajuan dan kemakmuran adalah pendidikan (Qodir. 2019). Sebagai gambaran yang tertulis pada website Pimpinan Pusat Muhammadiyah sejak tahun 2010 sampai 2020 lembaga pendidikan yang dikelola Muhammadiyah yaitu: Sekolah Dasar (SD)/MI) 2.604, Sekolah Menengah Pertama (SMP)/MTs 1.772, Sekolah Menengah Atas (SMA)/SMK/MA 1.143, Pondok Pesantren 67, Perguruan Tinggi Muhammadiyah 172 yang tersebar di Indonesia.

Dengan jumlah amal usaha dalam bidang pendidikan yang begitu banyak, Tanfidz Keputusan Muktamar Satu Abad Muhammadiyah menyatakan visi pengembangan program bidang Pendidikan Muhammadiyah adalah: berkembangnya kualitas dan ciri khas pendidikan Muhammadiyah yang unggul, holistik, dan bertata kelola baik yang didukung oleh pengembangan IPTEK dan LITBANG sebagai wujud aktualisasi gerakan dakwah dan tajdid dalam membentuk manusia yang utuh sebagaimana tujuan pendidikan Muhammadiyah (Muhamamdiyah.2010).

Perguruan Tinggi Muhammadiyah sebagai bagian dari amal usaha Muhammadiyah bidang pendidikan tinggi yang merupakan salah satu kekuatan Muhammadiyah dalam mencapai tujuan pendidikan Muhammadiyah perlu diselenggarakan berdasarkan peraturan Persyarikatan Muhammadiyah yang tertuang pada Pedoman Pimpinan Pusat Muhammadiyah Nomor 02/PED/I.0/B/2012 tentang Perguruan Tinggi Muhammadiyah dan peraturan perundangan pemerintah yang tercantum dalam Undang-undang Nomor 12 Tahun 2012 tentang perguruan tinggi.

Penelitian ini bertujuan untuk mengkaji dan menjelaskan kecenderungan visi perguruan tinggi Muhammadiyah khususnya universitas sebagai rencana strategis yang dimaknai dari visi universitas dalam rangka mendukung ketercapaian visi dan misi dakwah Muhammadiyah. Selain itu bahwa identifikasi kecenderungan visi Perguruan tinggi Universitas Muhammadiyah sebagai rencana strategis organisasi dalam mencapai tujuannya dapat memberikan arah dan peta kebijakan Majelis Dikti Pimpinan Pusat Muhammadiyah dalam pembinaannya. Dengan dua tujuan tersebut di atas, pertanyaan penelitian ini adalah apa kecenderungan visi universitas 
sebagai rencana strategis dalam rangka mendukung misi dakwah persyarikatan Muhammadiyah?.

\section{METODE}

Penelitian ini menggunakan Analisis Conten (Conten Analisis) dengan jenis Analisis Penunjukan (Designation Analysis) atau juga disebut dengan (Subject Mater Content Analysis) yakni menghitung frekuensi berapa sering konsep digunakan pada pernyataan visi Universitas Muhammadiyah sebagaimana tertulis dalam website resmi universitas (Krippendorff, 1980). Sampel penelitian sebanyak 57 Universitas Muhammadiyah di bawah naungan Majelis Dikti Persyarikatan Muhammadiyah.

Pengumpulan data pada penelitian ini dilakukan pada bulan Oktober-November dari pernyataan visi universitas sebagai rencana strategisnya pada 57 universitas Muhammadiyah yang dipublikasikan di website resmi universitas. Analisis Penunjukan (Designation Analysis) digunakan untuk menganalisis konsep yang digunakan pada visi dan misi Universitas Muhammadiyah dengan terlebih dahulu membuat kategori untuk mengidentifikasi seberapa banyak kecenderungan konsep tersebut muncul pada pernyataan visi universitas yang diteliti (Krippendorff, 1980).

Untuk menganalisis kecenderungan pernyataan visi dan misi sebagai rencana strategis universitas Muhammadiyah, pertama dilakukan pengunduhan visi dan misi melalui website resmi universitas. Kemudian pernyataan visi dianalisis dengan rumusan kategori konsep yang dihasilkan dengan merujuk pada Pedoman Pimpinan Pusat Muhammadiyah Nomor 02/PED/I.0/B/2012 tentang Perguruan Tinggi Muhammadiyah dan Undang-undang Nomor 12 Tahun 2012 tentang Perguruan Tinggi. Hasil rumusan kategori konsep tersebut sebagaimana pada tabel 1:

\section{Tabel 1.}

Kategorisasi Konsep

\begin{tabular}{|c|c|c|c|}
\hline \multirow[b]{2}{*}{ No. } & \multicolumn{2}{|c|}{ Sumber } & \multirow[b]{2}{*}{ Kategori } \\
\hline & $\begin{array}{l}\text { Pedoman PTM No. } \\
\text { 02/PED/I.0/B/2012 }\end{array}$ & UU No 12 Tahun 2012 & \\
\hline 1 & $\begin{array}{l}\text { Berkembangnya } \\
\text { kualitas dan ciri khas } \\
\text { pendidikan } \\
\text { Muhammadiyah }\end{array}$ & $\begin{array}{l}\text { Menjadi manusia yang } \\
\text { beriman dan bertakwa } \\
\text { kepada Tuhan Yang } \\
\text { Maha Esa dan } \\
\text { berakhlak mulia, sehat, } \\
\text { berilmu, cakap, kreatif, } \\
\text { mandiri, terampil, }\end{array}$ & $\begin{array}{c}\text { Pengembangan catur } \\
\text { darma }\end{array}$ \\
\hline
\end{tabular}


TAMADDUN : Jurnal Pendidikan dan Pemikiran Keagamaan

P-ISSN : 1693-3941; E-ISSN : 2722-2632

Vol. 22 No.1 Bulan Januari Tahun 2021

\begin{tabular}{|c|c|c|c|}
\hline & & $\begin{array}{l}\text { kompeten, dan } \\
\text { berbudaya }\end{array}$ & \\
\hline 2 & Unggul & $\begin{array}{l}\text { Penguasaan cabang } \\
\text { Ilmu Pengetahuan dan } \\
\text { atau Teknologi untuk } \\
\text { memenuhi kepentingan } \\
\text { nasional dan } \\
\text { peningkatan daya saing } \\
\text { bangsa }\end{array}$ & $\begin{array}{c}\text { Pengembangan } \\
\text { Karakter }\end{array}$ \\
\hline 3 & Holistik & $\begin{array}{l}\text { Menghasilkan Ilmu } \\
\text { Pengetahuan dan } \\
\text { Teknologi melalui } \\
\text { Penelitian yang } \\
\text { memperhatikan dan } \\
\text { menerapkan nilai } \\
\text { Humaniora }\end{array}$ & $\begin{array}{c}\text { Pengembangan } \\
\text { IPTEK }\end{array}$ \\
\hline 4 & Bertatakelola Baik & $\begin{array}{l}\text { Terwujudnya } \\
\text { Pengabdian kepada } \\
\text { Masyarakat berbasis } \\
\text { penalaran dan karya } \\
\text { Penelitian }\end{array}$ & Keunggulan \\
\hline 5 & $\begin{array}{l}\text { Pengembangan } \\
\text { IPTEK }\end{array}$ & & Tatakelola \\
\hline 6 & & & Penelitian \\
\hline 7 & & & $\begin{array}{l}\text { Pengabdian } \\
\text { Masyarakat }\end{array}$ \\
\hline
\end{tabular}

Dari identifikasi kategorisasi konsep sebagaimana tabel1, maka dirumuskan kategori untuk menganalisis kecenderungan visi dan misi universitas Muhammadiyah sebagai berikut: (1) pengembangan catur darma PTM (Al Islam dan Kemuhammadiyahan, (2) pengembangan karakter, (3) pengembangan IPTEK, (4) Keunggulan, (5) tata kelola, (6) penelitian, dan (7) pengabdian masyarakat.

Setelah dilakukan identifikasi sebagaimana kategori-kategori konsep terhadap pernyataan visi dan misi universitas berdasarkan kategori yang sudah ditetapkan. Selanjutnya adalah menghitung banyaknya frekuensi pada masing-masing kategori dan membuat persentase 
sehingga diketahui kategori yang terbanyak yang sering muncul dan menarik kesimpulan terhadap konsep yang sering digunakan pada pernyataan visi dan misi universitas.

\section{HASIL DAN PEMBAHASAN}

Dari hasil analisis terhadap pernyataan 57 visi universitas Muhammadiyah dengan kategori yang dibuat yakni; (1) pengembangan catur darma PTM Al Islam dan Kemuhammadiyahan (AIK) terdapat 43 pernyataan (75\%), (2) pengembangan karakter terdapat 9 pernyataan $(15,7 \%),(3)$ pengembangan IPTEK terdapat 28 pernyataan $(28 \%)$, (4) keunggulan terdapat 40 pernyataan $(70 \%)$, (5) tata kelola terdapat 1 pernyataan $(1,7 \%),(6)$ penelitian terdapat 3 pernyataan $(5,2 \%)$ dan $(7)$ pengabdian masyarakat terdapat 2 pernyataan $(3,5 \%)$.

\section{Tabel 2.}

Rangking Kecenderungan Konsep Pernyataan Visi Universitas Muhammadiyah

\begin{tabular}{|c|c|c|c|c|}
\hline No & Kategori & $\begin{array}{c}\text { Jumlah } \\
\text { Pernyataan }\end{array}$ & Persentase & Rangking \\
\hline 1 & Catur Darma PTM (AIK) & 43 & $75 \%$ & 1 \\
\hline 2 & Karakter & 9 & $15,7 \%$ & 4 \\
\hline 3 & Pengembangan IPTEK & 28 & $28 \%$ & 3 \\
\hline 4 & Keunggulan & 40 & $70 \%$ & 2 \\
\hline 5 & Tata kelola & 1 & $1,7 \%$ & 7 \\
\hline 6 & Penelitian & 3 & $5,2 \%$ & 5 \\
\hline 7 & Pengabdian & 2 & $3,5 \%$ & 6 \\
\hline
\end{tabular}

Selain kecenderungan konsep yang telah dikategorisasikan sebagaimana disajikan pada tabel 2, konsep lain yang muncul pada pernyataan visi universitas Muhammadiyah adalah (lihat Tabel.3): Enterpreneur/Teknopreneur sebanyak 11 pernyataan (19,2\%), Pengakuan Internasional sebagai World Class University (WCU) sebanyak 4 pernyataan (7\%), Pengakuan Regional dan Nasional sebanyak 5 pernyataan (8,7\%), Pengakuan negara ASEAN sebanyak 1 pernyataan (1,7\%), Pusat Arah Perubahan sebanyak 1 pernyataan (1,7\%), Kampus Modern sebanyak 2 pernyataan (3,5\%), Kampus Dakwah sebanyak 1 pernyataan (1,7\%), Profesional sebanyak 4 pernyataan (7\%), Inovatif sebanyak 3 pernyataan (5,2\%), Produktif sebanyak 1 pernyataan (1,7\%), Daya Saing sebanyak 5 pernyataan $(8,7 \%)$, Mandiri sebanyak 5 pernyataan $(8,7 \%)$, Peduli Budaya sebanyak 2 pernyataan (3,5\%), Kebangsaan sebanyak 2 pernyataan (3,5\%), Peduli Lingkungan sebanyak 1 pernyataan $(1,7 \%)$, Kearifan local sebanyak 3 
TAMADDUN : Jurnal Pendidikan dan Pemikiran Keagamaan

P-ISSN : 1693-3941; E-ISSN : 2722-2632

Vol. 22 No.1 Bulan Januari Tahun 2021

pernyataan (5,2\%), Integrasi keilmuan sebanyak 2 pernyataan (3,5\%), Wawasan Global sebanyak 2 pernyataan (3,5\%), Kampus bermartabat sebanyak 1 pernyataan $(1,7 \%)$.

Tabel 3.

Kecenderungan Konsep Pernyataan Visi Universitas Muhammadiyah selain dalam kategori

\begin{tabular}{|c|c|c|c|}
\hline No. & Kategori & $\begin{array}{c}\text { Jumlah } \\
\text { Pernyataan }\end{array}$ & Persentase \\
\hline 1 & Enterpreneur/Tecnopreneur & 11 & $19.2 \%$ \\
\hline 2 & World Class University (WCU) & 4 & $7 \%$ \\
\hline 3 & $\begin{array}{c}\text { Pengakuan Regional dan } \\
\text { Nasional }\end{array}$ & 5 & $8,7 \%$ \\
\hline 4 & Pengakuan dari Negara Asean & 1 & $1,7 \%$ \\
\hline 5 & Pusat Arah Perubahan & 1 & $1,7 \%$ \\
\hline 6 & Kampus Modern & 2 & $3,5 \%$ \\
\hline 7 & Kampus Dakwah & 1 & $1,7 \%$ \\
\hline 8 & Profesional & 4 & $7 \%$ \\
\hline 9 & Inovatif & 3 & $5,2 \%$ \\
\hline 10 & Produktif & 1 & 1,7 \\
\hline 11 & Daya Saing & 5 & $8,7 \%$ \\
\hline 12 & Mandiri & 5 & $8,7 \%$ \\
\hline 13 & Peduli Budaya & 2 & $3,5 \%$ \\
\hline 14 & Nasionalisme/Kebangsaan & 2 & $3,5 \%$ \\
\hline 15 & Peduli Lingkungan & 1 & 1,7 \\
\hline 16 & Kearifan lokal & 3 & $5,2 \%$ \\
\hline 17 & Integrasi Keilmuan & 2 & $3,5 \%$ \\
\hline 18 & Wawasan Global & 2 & $3,5 \%$ \\
\hline 19 & Kampus Bermartabat & 1 & 1,7 \\
\hline
\end{tabular}

Berdasarkan analisis kecenderungan penggunaan konsep pada pernyataan visi universitas Muhammadiyah (Tabel:2), temuan penelitian ini mengindikasikan bahwa kategori catur darma PTM (AIK) adalah konsep yang memiliki frekuensi tertinggi yakni sebanyak 43 pernyataan (75\%). Kategori tersebut diidentifikasi dengan kemiripan dan kedekatan makna yang terkandung dalam pernyataan visi, yakni; "Islam", "Islami”, "Islamic" "nilai-nilai Islam", "ke-

TAMADDUN Homepage : http://journal.umg.ac.id/index.php/tamaddun 
Islaman", "moral agama", "IMTAQ (iman dan taqwa)","Al Islam dan Kemuhammadiyahan (AIK)".

Catur darma pada perguruan tinggi Muhammadiyah adalah pendidikan, penelitian dan pengabdian masyarakat serta pengembangan Al Islam dan Kemuhammadiyahan (AIK). Sebagai darma ke-4 (empat) perguruan tinggi Muhammadiyah, tujuan pengembangan AIK adalah: (1) berkembangnya potensi manusia yang beriman dan bertakwa kepada Allah SWT, berakhlak mulia, cerdas, berilmu, cakap, kreatif, dan mandiri sehingga terwujud masyarakat Islam yang sebenar-benarnya, (2) terwujudnya kemampuan penciptaan, pengembangan, dan

penyebarluasan ilmu pengetahuan, teknologi, dan seni yang memberikan kemaslahatan bagi masyarakat, bangsa, negara, serta umat manusia, dan (3) terbinanya ke-Islaman dan Kemuhammadiyahan yang mencerdaskan dan mencerahkan bagi seluruh civitas akademika dan kehidupan yang lebih luas (Pedoman PTMA. 2016).

Agama Islam sebagai agama yang dianut oleh mayoritas masyarakat Indonesia masih menjadi rencana strategis yang dituangkan pada pernyataan visi universitas. Pernyataan yang berkaitan dengan kata "Islam" menunjukkan bahwa universitas memiliki cita-cita dengan menekankan nilai-nilai, prinsip-prinsip Islam dalam pengelolaan universitas untuk mencapai tujuannya (Sakdiah.2014). Penekanan tersebut dioperasionalkan oleh universitas dalam program, kegiatan, kurikulum, budaya organisasi (Ouchi, dkk. 1985); (Muhammad.2018), perilaku organisasi (Edwards, dkk. 2002) melalui serangkaian rumusan dokumen yang dijadikan pedoman oleh warga kampus.

Pernyataan Islam sebagai Agama dalam visi Universitas Muhammadiyah, juga sebagai penciri universitas (Frimin and Gilson.2009); (Ouchi.1981), strategi branding untuk menarik calon mahasiswa (Herawati.2019); (Ummah.2019), jaminan kualitas pengelolaan kepada stakeholders pendidikan (Purba.2009), implementasi rencana strategis nasional dalam bidang pendidikan (Suryadi.2016).

Kecenderungan penggunaan konsep frekuensi tertinggi kedua adalah kategori "unggul". Sebagaimana temuan dari analisis data pada visi universitas Muhammadiyah, terdapat 40 pernyataan (70\%), konsep "unggul" dengan persamaan makna "unggul", "terdepan", "terkemuka", "terpercaya". Konsep "unggul" sebagaimana ditemukan dari pernyataan visi universitas, mengandung dua makna yakni unggul secara universitas dan unggul dalam hal luaran yakni mutu lulusan mahasiswa.

Universitas yang unggul jika merujuk pada klasterisasi perguruan tinggi yang dilakukan oleh Kementerian Riset, Teknologi dan Pendidikan Tinggi Direktorat Jenderal Kelembagaan Ilmu Pengetahuan, Teknologi dan Pendidikan Tinggi meliputi beberapa aspek yakni: input, proses, ouput dan outcome. Para aspek input perguruan tinggi di nilai unggul dengan indikator: dosen berpendidikan S3, dosen dalam jabatan lector kepala dan guru besar, rasio jumlah mahasiswa terhadap dosen, jumlah mahasiswa asing dan jumlah dosen asing. Aspek proses 
dengan indikator; penggunaan pembelajaran daring (SPADA), kelengkapan laporan DIKTI, laporan keuangan, kerja sama perguruan tinggi, akreditasi program studi oleh BAN-PT, akreditasi institusi oleh BAN-PT. Pada aspek output meliputi: kinerja kemahasiswaa. Jumlah artikel ilmiah terindeks per dosen, kinerja penelitian, jumlah program studi terakreditasi internasional. Sedangkan pada aspek outcome meliputi: kinerja inovasi, jumlah patient per dosen, jumlah sitasi per dosen, kinerja pengabdian kepada masyarakat, persentase lulusan yang memperoleh pekerjaan dalam waktu 6 bulan.

Pengembangan IPTEKS adalah kecenderungan tertinggi ketiga dengan 28 pernyataan (28\%) yang ditemukan pada pernyataan visi universitas Muhammadiyah. Sebagaimana Undang-undang Nomor 12 tahun 2012 pasal 4 Pendidikan Tinggi berfungsi untuk mengembangkan Ilmu Pengetahuan dan Teknologi dengan memperhatikan dan menerapkan nilai Humaniora. Sedangkan pada pasal 5 bahwa pendidikan tinggi bertujuan dihasilkannya Ilmu Pengetahuan dan Teknologi melalui Penelitian yang memperhatikan dan menerpakan nilai Humaniona agar bermanfaat bagi kemajuan bangsa, serta kemajuan peradaban dan kesejahteraan umat manusia. Konsep pengembangan Ilmu Pengetahuan dan Teknologi pada pernyataan visi universitas Muhammadiyah sebagai rencana strategis belum menjadi prioritas. Hal tersebut diketahui bahwa hanya 28 pernyataan (28\%) dari 57 universitas yang diteliti.

Konsep pengembangan karakter pada pernyataan visi Universitas Muhammadiyah sebanyak 9 pernyataan (15,7\%). Konsep pendidikan karakter menjadi kecenderungan ke-4 masih memiliki relevansi dengan kondisi bangsa Indonesia karena menjadi agenda bersama untuk disukseskan sejak tahun 2010 dan dipertegas tahun 2016 melalui butir Nawacita dan Gerakan Nasional Revolusi Mental (GNRM) yang digembor-gemborkan pemerintah, perlu mendapatkan dukungan seluruh lembaga pendidikan untuk menyukseskannya.

Selain itu pendidikan karakter juga sesuai dengan pendidikan Muhammadiyah sebagai Pendidikan Islam modern yang mengintegrasikan agama dengan kehidupan dan antara iman dan kemajuan holistik untuk melahirkan generasi muslim terpelajar, berkarakter, memiliki kekuatan iman dan kepribadian manusia yang dapat menjawab tantang zaman dengan memiliki ilmu yang tinggi dengan kedalaman dan keluasan berpikir, berakhlak mulia, berpemikiran, bersikap dan bertindak berbasis Islam, sebagai role model, mandiri, peduli sesama, amar ma'ruf nahi mungkar, berdaya saing, profesional dalam bidangnya, berkemajuan dan mencerahkan.

Secara pengertian sebagaimana dalam UU PT No.12 Tahun 2012 bahwa penelitian adalah kegiatan yang dilakukan menurut kaidah dan metode ilmiah secara sistematis untuk memperoleh informasi, data, dan keterangan yang berkaitan dengan pemahaman dan/atau pengujian suatu cabang ilmu pengetahuan dan teknologi. Meskipun konsep penelitian sebagaimana kategorisasi pernyataan visi universitas Muhammadiyah terdapat 3 pernyataan $(5,2 \%)$ atau dalam kategori rendah, namun jika dilihat dari output penelitian menunjukkan hal memuaskan. Hal tersebut dapat dilihat hasil publikasi dosen dari 35 Universitas Muhammadiyah yang diambil sampel pada situs sinta.ristekbrin.go.id yang terindexs scopus 
sebanyak 3.774 artikel, terindeks WOS sebanyak 127 artikel dan 71988 artikel pada Google Schoolar.

Selanjutnya, sebanyak 2 pernyataan atau sebesar (3.5\%) kategori konsep pengabdian masyarakat sebagaimana visi pada 57 Universitas Muhammadiyah yang menjadi subjek penelitian. Hasil tersebut menunjukkan bahwa konsep pengabdian masyarakat sebagai salah satu pilar berdirinya perguruan tinggi masih belum menjadi ciri dari universitas di bawah naungan Majelis Dikti Muhammadiyah.

Pengabdian kepada masyarakat adalah kegiatan sivitas akademika yang memanfaatkan Ilmu Pengetahuan dan Teknologi untuk memajukan kesejahteraan masyarakat dan mencerdaskan kehidupan bangsa (UU PT No.12 Tahun 2012). Pengabdian masyarakat merupakan kegiatan yang menghubungkan hasil penelitian dan penguasaan disiplin ilmu dalam pendidikan disatu sisi dengan peningkatan kualitas pendidikan dan pengembangan penelitian pada sisi lainnya. Pengabdian masyarakat difungsikan sebagai penunjang pembangunan pada lapisan masyarakat. Dengan adanya pengabdian masyarakat dari perguruan tinggi diharapkan perguruan tinggi bukan hanya sebagai mercusuar keilmuan namun juga sebagai lembaga yang dapat menjadi solusi bagi masyarakat terkait masalah-masalah kemasyarakatan.

Pernyataan visi terhadap pernyataan "tata kelola" sebanyak 1 pernyataan $(1,7 \%)$. Hal ini mengindikasikan bahwa tata kelola universitas Muhammadiyah belum menjadi prioritas dalam rencana strategis mereka. Tata kelola atau manajemen perguruan tinggi sebenarnya menjadi hal yang sangat penting dikarenakan dengan tata kelola yang baik akan menghasilkan mutu yang baik. Dengan adanya tata kelola perguruan tinggi yang baik dapat memberikan kewenangan perguruan tinggi untuk melakukan kontrol terhadap sumber daya manusia, dan fleksibilitas dalam merespons kebutuhan masyarakat.

Tata kelola perguruan tinggi bermakna bahwa kewenangan untuk pengembangan pendidikan dan langkah-langkah prioritas diperkenankan dengan tetap mengacu pada standar pemerintah, perbaikan berkelanjutan dari hasil monitoring dan evaluasi pada setiap kemajuan yang telah dicapai untuk peningkatan mutu. Dengan makna tersebut tata kelola yang efektif akan mampu merespons kebutuhan stakeholders pendidikan secara cepat dan tepat khususnya mutu perguruan tinggi. Dengan demikian bahwa dengan tata kelola yang efektif melalui serangkaian proses manajemen pada aspek perencanaan, pelaksanaan dan pengendalian, perguruan tinggi akan mampu menetapkan dan mewujudkan tujuannya sebagaimana tercantum dalam rencana strategis yang tertuang dalam visinya.

Pengaruh visi dalam mengerakkan seluruh komponen yang dalam organisasi sangat penting sehingga penentuan visi benar-benar harus mampu memberikan inspirasi dan motivasi kepada seluruh civitas organisasi (Stephen And Morgan. 1994). Hal tersebut sesuai dengan pernyataan Guven (2011) "The success of the strategic plan depends on the correct formulation of mission and vision state $\neg$ ments, and wide participation in their formulation. Mission and 
TAMADDUN : Jurnal Pendidikan dan Pemikiran Keagamaan

P-ISSN : 1693-3941; E-ISSN : 2722-2632

Vol. 22 No.1 Bulan Januari Tahun 2021

vision statements also contribute to the creation of the institutional identity of an or-ganization. Mission statement introduces the or $\neg$ ganization to the public and distinguishes it from other organizations by emphasizing its unique characteristics." Kedudukan pentingnya visi sebagai rencana strategis universitas tidak hanya sebagai jargon belaka, sehingga perlu dirumuskan dengan sungguh-sungguh, tertulis dan disosialisasikan kepada seluruh stakeholders agar dimiliki kesadaran oleh seluruh warga organisasi serta sebagai pemandu pimpinan organisasi dalam mengarahkan tujuan organisasi yang dipimpinnya (Hamdan. 2001).

Pentingnya visi juga ditegaskan dalam Al-Qur'an dalam Surah Al Hasr ayat 18 yang artinya "Wahai orang-orang yang beriman! Bertakwalah kepada Allah dan hendaklah setiap orang memperhatikan apa yang telah diperbuatnya untuk hari esok (akhirat), dan bertakwalah kepada Allah. Sungguh, Allah Mahateliti terhadap apa yang kamu kerjakan (Q.s. Al Hasyr ; $59 ; 18)$

\section{SIMPULAN}

Pernyataan visi sebagai rencana strategis pada universitas Muhammadiyah sebagaimana hasil Analisis Konten (Content Analysis) yang dilakukan terhadap 57 Universitas Muhammadiyah, belum secara optimal menunjukkan pencapaian terhadap visi Persyarikatan Muhammadiyah khususnya bidang Pendidikan Tinggi dan juga fungsi serta tujuan yang tertuang dalam undang-undang no 12 tahun 2012 tentang perguruan tinggi. Kurangnya optimalisasi tersebut diindikasikan pada kategori konsep-konsep sebagai berikut: (1) pengembangan karakter terdapat 9 pernyataan $(15,7 \%)$, (2) pengembangan IPTEK terdapat 28 pernyataan $(28 \%)$, (3) tata kelola terdapat 1 pernyataan $(1,7 \%)$, (4) penelitian terdapat 3 pernyataan $(5,2 \%)$ dan $(5)$ pengabdian masyarakat terdapat 2 pernyataan $(3,5 \%)$.

\section{REFERENSI}

David, F., Fred. 2011. Strategic Management: Concept and Cases (13th ed). Boston: Pearson Education.

Edwards, Ronald W., Pooja Kumar, and Ruby Ranjan. 2002. "Understanding organisation culture and innovation: a case study approach." Sixth International Research Conference on Quality, Innovation and Knowledge Management held in Malaysia in February.

Firmin, Michael W., and Krista Merrick Gilson. 2009. "Mission Statement Analysis of CCCU Member Institutions." Christian Higher Education 9.1: 60-70.

doi.org/10.1080/15363750903181922

Gaspersz, Vincent. 2004. Perencanaan strategik untuk peningkatan kinerja sektor publik. Jakarta: PT Gramedia Pustaka Utama

https://Muhammadiyah.or.id 
https://www.webometrics.info/en/asia/indonesia $\% 20$

https://sevima.com/8-universitas-terbaik-di-indonesia-2021/

Haim, Hilman Abdullah. 2005. Pengurusan Strategic Malaysia: McGraw-Hill.

Hamdan, Yusuf. "Pernyataan Visi dan Misi Perguruan Tinggi. 2001. " Mimbar: Jurnal Sosial dan Pembangunan, vol. 17, no. 1, pp. 90-103. DOI: https://doi.org/10.29313/mimbar.v17i1.34

Herawati, Tetty, Arianis Chan, and Herwan A. Muhyi. 2019. "Universitas Padjadjaran Dalam Perspektif Corporate Brand Dalam Rangka Mencapai Visi Tahun 2026." AdBispreneur: Jurnal Pemikiran dan Penelitian Administrasi Bisnis dan Kewirausahaan 3.3 : 207-217. https://doi.org/10.24198/adbispreneur.v3i3.19792

Krippendorff, Klaus. 1980. Analisis Isi: Pengantar Teori dan Metodologi (alih bhs. Farid Wajidi). Jakarta: PT. Raja Grafindo Persada.

Muhammad, Syuaiban. 2018. "Pentingnya pengembangan budaya organisasi pada perguruan tinggi." Jurnal Ilmiah WIDYA 4.3.

Mulyono. 2006. Penerapan Prinsip ISO 9001:2000 di Lembaga Pendidikan. Jurnal E1 Harakah, UIN Malang

Muhammadiyah, PP. 2010. Tanfidz Keputusan Muktamar Satu Abad Muhammadiyah.

Majelis Pendidikan Tinggi PP Muhammadiyah. 2016. Pedoman tentang Perguruan Tinggi Muhammadiyah.

Nuryana, Zalik. 2017. "Revitalisasi Pendidikan Al-Islam Dan Kemuhammadiyahan Pada Perguruan Muhammadiyah." TAMADDUN 18.1 : 1-11. DOI: http://dx.doi.org/10.30587/tamaddun.v0i0.87

Pitts, A., Robert \& Lei, David. 2006. Strategic Management (Building and Sustaining Competitive Advantage). Ed. ke 4. Australia: Thomson.

Porth, J., Stephen. 2003. Strategic Management (a cross-functional approach). New Jersey: Prentice Hall.

Purba, Sukarman. 2009. "Reformasi Pendidikan dalam Meningkatkan Mutu Lulusan Perguruan Tinggi." Jurnal Generasi Kampus. Vol.2, No.1

Ozdem, G, 2011. An analysis of the mission and vision statements on the strategic plans of higher education institutions. Educational Sciences: Theory and Practice, 11(4), 18871894.

Ouchi, William G., and Alan L. Wilkins. 1985. "Organizational culture." Annual review of sociology $11.1: 457-483$.

Ouchi, William. G. 1981. Theory Z. New York: Addison-Wesley 
TAMADDUN : Jurnal Pendidikan dan Pemikiran Keagamaan

P-ISSN : 1693-3941; E-ISSN : 2722-2632

Vol. 22 No.1 Bulan Januari Tahun 2021

Qodir, Zuly. 2019. "Islam Berkemajuan Dan Strategi Dakwah Pencerahan Umat." Jurnal Sosiologi Reflektif 13.2 : 209-234. DOI: https://doi.org/10.14421/jsr.v13i12.1630

Rahardja, Untung, Endah Nirmala Dewi, and Ninda Lutfiani. 2017. "Peningkatan Rank Webometrics Menggunakan Metode Inbound Dan Outbound Pada Perguruan Tinggi." Sisfotenika 7.1 : 1-12. DOI: http://dx.doi.org/10.30700/jst.v7i1.129

Suryadi, Rudi Ahmad. 2016. "Visi dan Paradigma Pendidikan Agama Islam (PAI): Kualitas, Integratif, dan Kompetitif." EDUKASI: Jurnal Pendidikan Islam 4.2: 253-276.

Suyanti, Esti. 2011."Strategi internasionalisasi dalam bidang penelitian pada Universitas Indonesia dan Institut Pertanian Bogor." Jurnal manajemen pendidikan 2.1: 10-21. DOI: https://doi.org/10.21009/jmp.02102

Sakdiah, Sakdiah. 2014. "Karakteristik Manajemen Organisasi Islam." Jurnal Al-Bayan: Media Kajian dan Pengembangan Ilmu Dakwah. 20.1. DOI: http://dx.doi.org/10.22373/albayan.v20i29.115

Surat Edaran Klaterisasi Perguruan Tinggi Indonesia Tahun 2019 nomor 1736/L8/SI/2019 Kementerian Riset, Teknologi dan Pendidikan Tinggi Direktorat Jenderal Kelembagaan Ilmu Pengetahuan, Teknologi dan Pendidikan Tinggi. pdf

Stephen Murgatroyd and Colin Morgan, 1994. Total Quality Management and The School, Buckingham-Philadelphia: Open University Press.

Ummah, Barirotul. 2019. "Strategi Image Branding Universitas Nurul Jadid Di Era Revolusi Industri 4.0." TARBIYATUNA 12.1: 59-81. https://doi.org/10.36835/tarbiyatuna.v12i1.352

Undang-undang Republik Indonesia Nomor 12 Tahun 2012 tentang Pendidikan Tinggi. Jakarta. Kemenristekditi 2012.

Wibowo. 2014. Perilaku Dalam Organisasi. Jakarta: Rajawali Press. 